\title{
Democratic Replay: Enhancing TV Election Debates with Interactive Visualisations
}

\author{
Brian Plüss \\ Centre for Argument Technology \\ University of Dundee \\ b.pluss@dundee.ac.uk
}

\author{
Anna De Liddo \\ Knowledge Media Institute \\ The Open University \\ anna.deliddo@open.ac.uk
}

\begin{abstract}
This paper presents an online platform for enhancing televised election debates with interactive visualisations. Election debates are one of the highlights of election campaigns worldwide. They are also often criticised as appearing scripted, rehearsed, detached from much of the electorate, and at times too complex. Democratic Replay enhances videos of election debates with a collection of interactive tools aimed at providing a replay experience centred around citizens' needs. We present the system requirements, design and implementation, and report on an evaluation based on the ITV Leaders' Debate from the 2015 UK General Election campaign.
\end{abstract}

\section{Introduction}

Televised election debates were first introduced in the United Kingdom in 2010: three 90-minute debates involving the leaders of the three main political parties. Research has shown that these events were greatly appreciated by the British public [1], with three-quarter of viewers agreeing that they knew more about the quality of the leaders after the debates. The debates also seem to have energised first-time voters and there is evidence that they were discussed afterwards [2]. The experience was repeated in the 2015 General Election, with two debates: the 7-party Leaders' Debate and a 5-party Challengers' Debate. The Guardian reported seven million people watching the Leaders' Debate, while The Telegraph reported more than 1.5 million tweets sent, with an average of 8,657 tweets per minute.

This shows that social media and ubiquitous computing devices are changing the way audiences experience such complex broadcast [3, 4, 5]. Together with the live transmission, viewers have at hand streams of complementary information, produced by mainstream media and, increasingly more often, by other viewers. We address three challenges that arise in these scenarios: (a) the lack of organisation and structure between these many information streams and the televised event which can make the viewing experience confusing, overwhelming and inaccessible to some users; (b) the low levels of citizen access to and engagement with political contents; and (c) the inherent complexity of the results of in-depth analyses which can make their interpretations difficult to most viewers.

These challenges motivated the design and implementation of Democratic Replay: an interactive video replay platform in which information channels can be stored as hypermedia annotations and visualised in synchrony with the video of a debate. Democratic Replay addresses (a) by providing a free, consistent, structured and customisable enhanced viewing experience; (b) by using in-depth analytics and knowledge curation to allow democratic citizens to better access and engage with televised election debate content; and (c) by using dynamic visualisations and hypermedia technologies to provide intuitive interactive visualisations of complex debate dynamics.

We evaluated the system via a mixed user experience questionnaire and focus group workshop involving two groups of citizens based on their interest in politics. The aim of the evaluation was to determine the extent to which the interactive visualisations enhance the debate viewing experience, and how this experience is affected by people's interest in politics.

\section{Background and Related Work}

Our work sits at the crossroads of research in television and the internet, political communication, and hypermedia. In this section, we review relevant literature on these areas and identify three challenges in the context of public engagement with televised 
election debates, which served as high-level requirements for the design of Democratic Replay.

\subsection{Television and the Internet: the multimedia livingroom}

As said, the ways viewers engage with televised media events are changing. Second screens such as tablets and smartphones are now integrated in TVwatching habits, as viewers access media contents that can or cannot be related to those being televised [6]. As a result, TV consumption is shifting from an activity shared with other members of the household to a more individual experience, which could potentially involve the participation of thousand other viewers through social media $[6,4]$. Television itself is evolving. The HbbTV 2.0 industry standard [7] will enable television sets and handheld devices to synchronise over content, leading to enhanced, interactive viewing experiences (e.g., via companion mobile apps) and creating potential for novel applications [8, 9].

These changes bring about opportunities. Most significantly, second screens enable the enhancement of televised events towards interactive experiences that can be tailored to individual viewers $[10,11]$. The development of programme-specific companion apps can organise and deliver these enhancements, both inbound by channelling streams of synchronised information from the internet to the viewers [12], and outbound by giving viewers a voice through dedicated comment channels and social media $[6,4]$ or via special-purpose audience feedback elicitation techniques [13].

These changes also present new challenges. First, second screens introduce distractions [14] and can make it difficult for viewers to effectively focus on the televised and additional contents at once $[12,6]$. Second, they interfere in the interactions between viewers in the same physical environment, especially when some of them do not have access to the same devices or contents [6]. Third, new media could result alienating for individuals or social groups who are not technologically savvy, who do not have access to the secondary information streams or who are not involved in social media [15]. The 'knowledge gap hypothesis' [16] links access to new media to socioeconomic status and predicts that those without access to information technologies will be in disadvantage. Although traditional media (TV, radio and newspapers) are still the main source of current affairs and political knowledge, as second screens and the internet become more pervasive in the consumption of television, this might increase the differences in knowledge also for current affairs and political news based on socio-economic access. Based on these research gaps, we build the first challenge for technology design, that is:

Challenge 1. Giving access to a wide range of citizens to a non-intrusive enhanced televised election debate viewing experience.

\subsection{Political Communication: new media and live political events}

The observations above also hold for citizen engagement with political media events such as televised election debates [3, 1, 2, 18, 5]. Television presents itself as a medium producing a mix between popular culture and democratic public deliberation [15]. Combined with new media, this opens the possibility of more direct political representation and civic engagement [19], especially among young people [18].

Still, the challenge remains of organising the inbound and outbound information flows, of making the experience engaging and informative, and of giving citizens universal access to the new media $[20$, $21,15]$. In addition, citizen engagement with enhanced televised election debates share the impediments of other aspects of democratic participation, including failures in civic education, citizen apathy, and the disconnection between citizens and politicians $[22,23]$.

Coleman [15] identifies a set of requirements for democratic citizenship in connection with televised election debates, which we adopt for their technology-enhanced counterparts: 'being informed not about everything, but about enough to feel capable of contributing to the political conversation; being free to participate - not all the time, but at least some of the time; feeling engaged in the processes that affect their lives - at least to the point of not feeling like permanent outsiders; and experiencing a subjective belief that they have at least some chance of making a difference in the world.' [15, p. 10]. Based on this, we formulate the second challenge:

Challenge 2. Increasing citizens' access to and engagement with televised election debates by means of technological enhancements.

\subsection{Hypermedia: hypervideo for enhanced televised debates}

Hypervideo refers to video files that can be navigated via links, instead of linearly [24], much in the same way as hypertext. This belongs in a wider area of hypermedia, which applies the hyperlink navigation principle regardless of the media (e.g. text, sound, images, video) [25]. Hypercafe [26, 27] 
was the first special-purpose computer program to support video linking and accompanied the coinage of the term 'hypervideo'. Open source, generalpurpose technologies for implementing and deploying hypervideo over the Web include Popcorn.js and the HTML5 video tag. These allow for a video to be programmatically manipulated and, in practice, functionally linked with annotations, making it possible to use annotations to navigate the video non-linearly inside a browser.

Attempts to generate dynamic, interactive visualisations from hypervideo annotations have been scarce. Advene [28] is an open-source framework for integrating and visualising audiovisual metadata, used in a scholar context to assist active reading [29]. Recent versions of Compendium [30] include video mapping functionalities for knowledge, issue and argument maps to be created on top of and synchronised with a video [31]. One clear pitfall of these two tools is that they do not support web delivery of, access to and interaction with the resulting visualisations. Tools that provide web hypervideo, such as Popcorn, have been used to for flexible video indexing, but it is not known how this could be extended to interactive hypervideo visualisations. These shortcomings in available technologies lead us to the third challenge:

Challenge 3. Online delivery of interactive visualisations of hypervideo metadata in ways that are consistent, non-intrusive and accessible to a wide range of viewers.

\section{Democratic Replay}

We designed a video replay web application, accessible via personal computers and large handheld devices such as tablets. The high-level requirements for the design of this application follow from the three challenges above.

We designed and implemented a free and open platform in which access to the contents and to the tools are not limited by fees, memberships or proprietary licenses. We therefore opted for the development of an open data, open source mobile web application, as opposed to the use of devicespecific technologies (e.g. Apple's iOS or Android) or of pre-existing communities or social media platforms (e.g. Twitter, Facebook, Youtube). The information channels available to users are in line with the conclusions of Geerts et al. [12] for companion apps to televised programmes: among others, that the updates are non-trivial, no secondary videos, synchrony of the information presented with the first screen, etc. Additionally we developed specific techniques for turning hypervideo annotations into meaningful data streams or animated graphics that update as the video progresses [31]. Of central relevance is the use of hypervideo annotation technologies coupled with dynamic data visualisation libraries.

In a nutshell, in order to meet the challenges we detailed in the previous section, Democratic Replay is based on in-depth analyses and knowledge curation of available data sources (video, transcripts, debate rules, audience reactions, etc.), which are made freely and openly available in the form of synchronized, dynamic, and interactive visualisations.

\subsection{Platform Architecture and User Interface}

The platform architecture consists of three main components: the data sources, the hypermedia indexing repository and the visual analytics interface.

The Democratic Replay data workflow starts with the DATA SOURCES: the raw materials from which we produce the platform's contents (e.g. debate videos and transcripts, debates' Rules of Engagement, Twitter and viewer feedback data, party manifestos, Parliamentary reports, etc.). Data from these sources are imported into a HYPERMEDIA REPOSITORY. Several ANALYTICS AND VISUALISATIONS are produced semi-automatically from these data and added to the repository as hypermedia annotations. These are then packed with the debate and made available to viewers as interactive contents in DEMOCRATIC REPLAY. Figure 1 shows an overview of the ecosystem leading to Democratic Replay.

The main user interface consists of the video player, access to the full transcript of the debate (searchable and with a keywords linked to important themes highlighted), and a collection of dynamic widgets (see right hand side of Figure 1 for a snapshot of the UI). Each widget presents second-bysecond snapshots of a specific analysis and provides access to full-blown interactive visualisations as those shown in Figures 2 to 4.

\subsection{In-depth Data Analyses, Knowledge Curation and Dynamic Interactive Visualisations}

Democratic Replay offers a variety of in-depth analyses ( 7 in total) that shed light on the behaviours of the actors in public media events such as election debates, from politicians, to broadcasters and moderators, to other viewers. However, for the outcomes of these analyses to be of any use to a wide range of citizens, they need to be presented in ways 


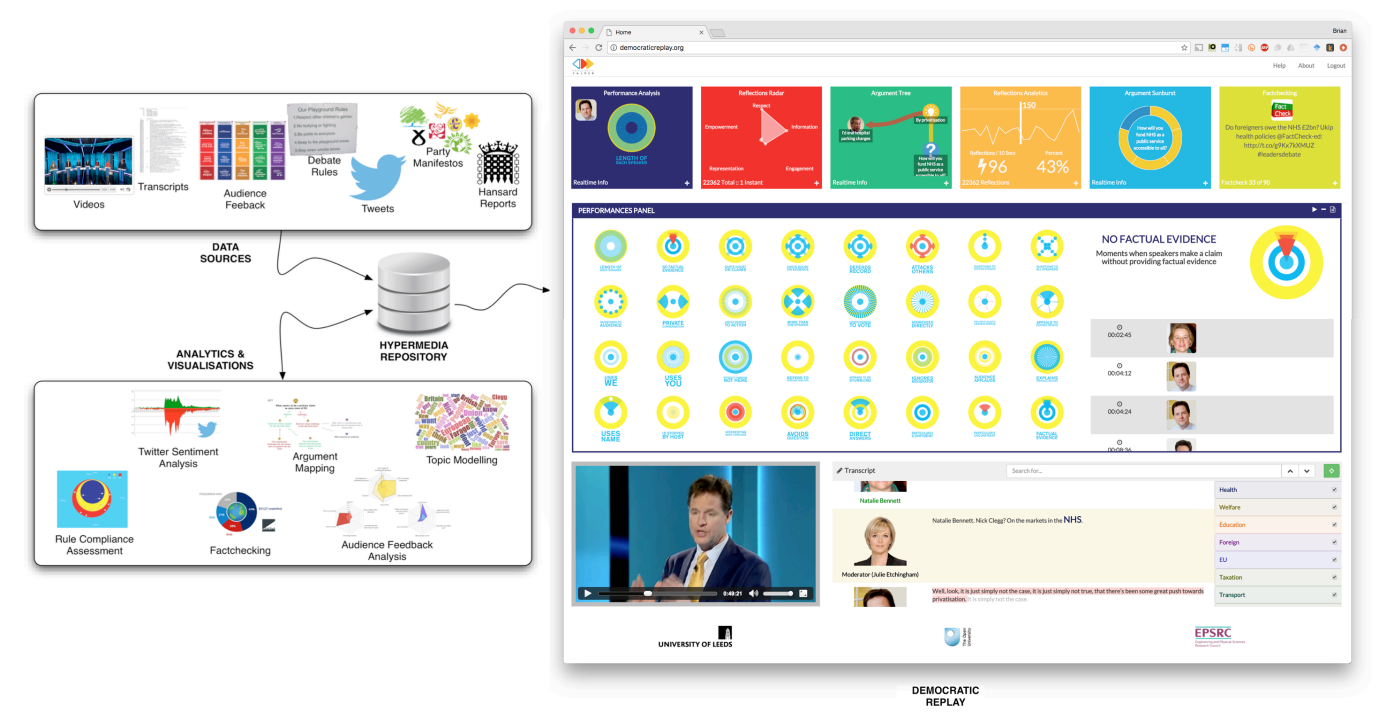

Figure 1. Overview of the election debate replay platform

that are accessible, intuitive, consistent and informative, in synchrony with the specific events in the debate to which they relate. This means that visualisations cannot be mere final aggregates of hypermedia annotations: they must have a life cycle, starting when the debate kicks off and evolving as the video is replayed. They also must be interactive, allowing viewers to zoom in and out at interesting moments, select relevant subsets of annotations, and jump to relevant parts of the video by clicking on specific sections of a visualisation.

In this paper we will focus on three of the analyses and visualisations currently supported by Democratic Replay:

1. The Arguments Tree: which visualises the argumentation structures of the debate;

2. The Speaker Performances Panel: which shows the qualitative assessment of the debaters' performance;

3. The Audience Reflections Radar: which represents the analysis of live audience responses.

These three interactive visualisations were chosen out of the 7 available to test with a variety of data analyses, as well as to maximise novelty and complexity in data interaction. Each visualisation comes from a specific analytical research strand and requires appropriate data curation. Figures 2, 3 and 4 show the interactive visualisations for the argumentation structures, the debaters' performance, and the live audience responses in the current implementation of Democratic Replay.

\subsubsection{The Arguments Tree: Computer Supported} Argumentation Visualisation. CSAV [33] is a field of study focused on the use of information technologies to help make sense of complex argumentation. The political issues covered in election debates are often inherently complex, which results in arguments that are beyond the understanding of most viewers. This causes citizens to feel excluded from the event, and ultimately leads to disengagement. Argument maps help to tackle the intellectual challenge posed by the complexity of issues and arguments in political discourse by making crucial elements of these visually explicit. They help viewers, for instance, to 'see' how the candidates are addressing key issues, the claims they make, whether they offer any evidence to substantiate these claims, and how the arguments they make relate to each other. CSAV includes several techniques for mapping argumentation. We used IBIS-based Issue and Dialogue Mapping [34, 35, 36] for crafting argument maps (strictly speaking, issue and dialogue maps, respectively) from election debates in Compendium [30]. The video mapping features of Compendium allow linking the elements in the maps (questions, issues, claims, and their relations) to specific points in the duration of a debate. This creates time-linked hypervideo annotations, which can be visualised dynamically in synchrony with the video. Therefore, after the time-indexed maps where created with Compendium, the annotated dataset was used to seed a new interactive visualization consisting of an expandable tree (see Figure 2). 


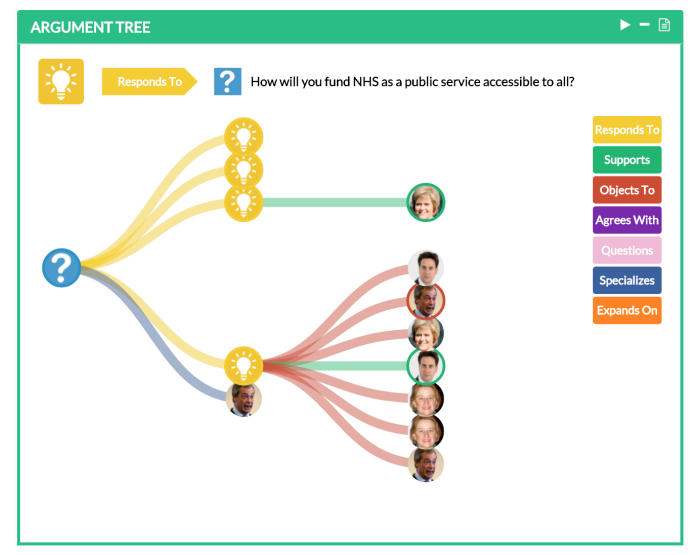

Figure 2. Interactive visualisation for argumentation structures: the Arguments Tree

This visualization allows people to replay the video with the argument tree unfolding as the video plays, at the crucial moments in which arguments are made.

\subsubsection{The Speaker Performances Panel:} Qualitative Analysis of Debaters' Performance. The analysis of the performance of participants of election debates takes on techniques from content analysis [37, 38]. A set of 32 variables were defined, encompassing actions that ranged from the behaviour of debaters with regards the debate questions, to interactions with each other and the audience, to body language and compliance with the rules of the debate. The entire transcript of the debate was annotated with these variables and an iconic language was defined to represent each annotation instantly. Figure 3 shows an image of the speakers' performance panel. As the video progresses, the list on the right scrolls, indicating the speaking and identifying a specific video fragment. The icon of a tagged performance is then highlighted in the top right area (see, for instance, the "No Factual Evidence" icon in Figure 3 ). The panel of icons on the left can be also used to explore the video by performance tag. By clicking on an icon, all the clips with that icon tag will be listed. Clicking on any of the speakers in the list will play the relevant fragment of the video.

\subsubsection{The Audience Reflections Radar:} Crowdsourcing Instant Audience Responses. We built on the approach by De Liddo et al. [13] and incorporated the results of their instant feedback method as one of the analytics visualised in Democratic Replay. The current method consists of 20 cards arranged in five dimensions based on the citizens entitlements in connection with televised elections debates identified by Moss and Coleman
[32]. A web-based digital implementation of De Liddo et al.'s approach is available via an online mobile website called Democratic Reflection, accessible from laptop computers and hand-held devices. With this application, viewers are able to click or touch on a list of 20 statements that represent their reflections during the debate. The application registers responses that are linked to a unique user identifier and to the current timestamp in the debate. These annotations are then analysed to give a rich understanding of the audience's assessment of the media event (see [13] and Figure 4 for details).

A new Interactive Visualisation was created to enable viewers to replay the audience reactions captured by Democratic Reflection as they occurred during the debate. The visualisation shows the spider diagram of the 20 audience reactions (coloured circles in Figure 4), also grouped by reaction type (5 main types are distinguished by colour: respect, information, engagement, representation, and empowerment). Various filters are available in the visualisation to navigate the video by reaction type.

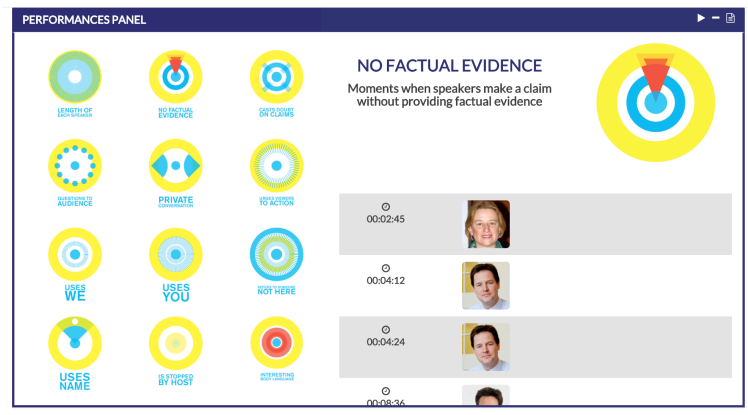

Figure 3. Visualisation for debaters' performance: the Speaker Performances Panel

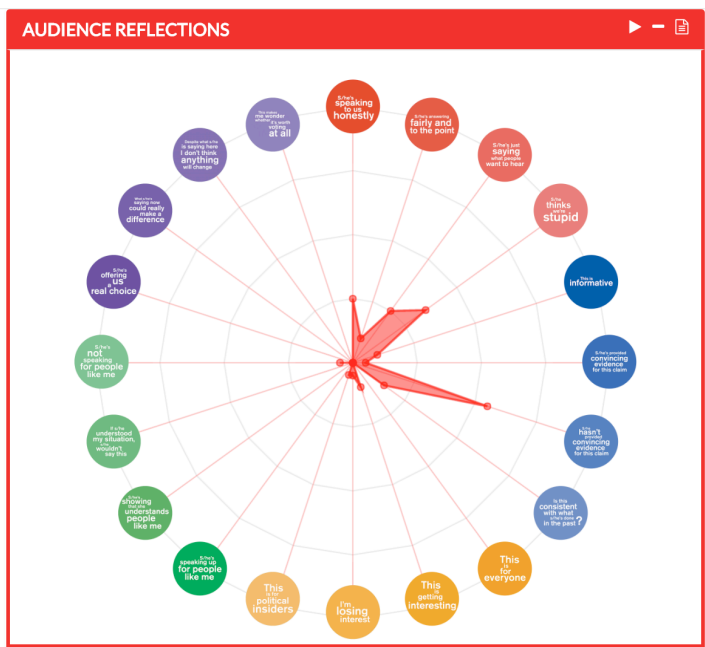

Figure 4. Visualisation for instant audience responses: the Audience Reflections Radar 


\section{Evaluation}

In order to assess Democratic Replay we carried out a user study to answer the following research questions:

RQ1. To what extent do the interactive visualisations available within Democratic Replay provide a viewing experience of the election debate that is attractive, perspicuous, efficient, supportive, stimulating and novel?

RQ2. Is there a difference in the assessment of Democratic Replay between users interested vs. not interested in politics?

In order to address the first research question we used the User Experience Questionnaire [39, 40], which provides a detailed assessment of the user experience under the six categories we targeted in RQ1: Attractiveness, Perspicuity, Efficiency, Dependability, Stimulation and Novelty. Table 1 shows the research sub questions that are addressed by each category.

The second research question is crucial in our goal of addressing low citizen engagement with politics. This motivated the separation of participants in two groups based on their interest in politics, allowing us to identify precisely the potential of Democratic Replay to attract the interest of people disengaged with politics.

We carried out a workshop in which two groups of citizens selected based on their interest in politics (Group 1: interested; Group 2: not interested) interacted with the tools shown in Figures 2 to 4. After each interaction, they were asked to fill in a user experience questionnaire. This was followed by a focus group discussions to find out the why and how of their experience. It is outside of the scope of this paper to present the result of the qualitative analysis of the focus group discussion. We focus instead on the quantitative analysis of the questionnaire to assess the users' experience with the interactive visualisations.

\subsection{Methodology}

Participants were shown a fragment of a televised election debate, after which they were introduced briefly to each one of the visualisation tools in Figures 2 to 4 . Following each explanation, they were asked to use the tools individually. Immediately after using the tools they were asked to complete the User Experience Questionnaire (UEQ) [39, 40]. This UX questionnaire requires participants to grade their experience across 26 items between two extremes on a 7-point scale (for facsimiles of the UEQ, guidelines and downloads, check http://www.ueq-online.org/).
These items then are grouped into 6 categories: Attractiveness, Perspicuity, Efficiency, Dependability, Stimulation and Novelty. As noted by Schrepp et al. [40, p. 385]: 'Attractiveness is a pure valence dimension. Perspicuity, Efficiency and Dependability are pragmatic quality aspects (goaldirected), while Stimulation and Novelty are hedonic quality aspects (not goal-directed).' Table 1 summarises the categories, the research sub-questions they address, and the items in the UEQ to which they are linked. These categories are further grouped into three hedonic and pragmatic quality aspects: attractiveness, pragmatic quality (Perspicuity, Efficiency, Dependability) and hedonic quality (Stimulation, Originality).

\begin{tabular}{lll} 
Table & $\begin{array}{c}\text { 1. Categories in the User Experience } \\
\text { Questionnaire }\end{array}$ \\
\hline Categories & RQ1 Sub-questions & Items (Scored -3,-3,-1,0,+1,+2,+3) \\
\hline Attractiveness & $\begin{array}{l}\text { Do users like or dis- } \\
\text { like the tool? }\end{array}$ & $\begin{array}{l}\text { annoying I enjoyable } \\
\text { good I bad } \\
\text { unlikeable I pleasing } \\
\text { unpleasant I pleasant } \\
\text { attractive I unattractive } \\
\text { friendly I unfriendly }\end{array}$ \\
\hline Perspicuity & $\begin{array}{l}\text { How easy is it for } \\
\text { users to get familiar } \\
\text { with the tool? }\end{array}$ & $\begin{array}{l}\text { not understandable I understandable } \\
\text { easy to learn I difficult to learn } \\
\text { complicated I easy } \\
\text { clear I confusing }\end{array}$ \\
\hline Efficiency & $\begin{array}{l}\text { Can users use the } \\
\text { tool without exces- } \\
\text { sive effort? }\end{array}$ & $\begin{array}{l}\text { fast I slow } \\
\text { inefficient I efficient } \\
\text { impractical I practical } \\
\text { organised I cluttered }\end{array}$ \\
\hline Dependability & $\begin{array}{l}\text { Do users feel in con- } \\
\text { trol of the interac- } \\
\text { tion? }\end{array}$ & $\begin{array}{l}\text { unpredictable I predictable } \\
\text { obstructive I supportive } \\
\text { secure I not secure } \\
\text { meets expectations I doesn't meet expectations }\end{array}$ \\
\hline Stimulation & $\begin{array}{l}\text { How exciting and } \\
\text { motivating is it to } \\
\text { use the tool? }\end{array}$ & $\begin{array}{l}\text { valuable I inferior } \\
\text { boring I exciting } \\
\text { not interesting I interesting } \\
\text { motivating I demotivating }\end{array}$ \\
\hline Novelty & $\begin{array}{l}\text { How innovative and } \\
\text { creative is the tool? }\end{array}$ & $\begin{array}{l}\text { creative I dull } \\
\text { inventive I conventional } \\
\text { usual I leading edge } \\
\text { conservative I innovative }\end{array}$ \\
\hline
\end{tabular}

In addition to the items in the UEQ, for each tool participants were asked to indicate the extent to which they agreed or disagreed (on a 5-point scale) with 8 statements which aimed to capture specific sensemaking effects of using the tool, such as improvement in the users' capability to focus, reflect, and change opinion. The statements read:

I found that using the tool...

- ...made me really focus on the debate.

- ...interfered with my watching of the video.

- ...changed some initial assumptions I had.

- ...made me reflect in a deeper way.

- ...reinforced what I believed already.

- ...provided me with unexpected insights on the debaters and on what they said. 
- ...helped me to reflect on the value and quality of televised political debates.

- ...changed the way I would like to be engaged in political debates in future.

\subsection{Study}

The study gathered 29 participants in two sessions of 120 minutes each. The groups were mixed in terms of gender and age, and differed in their interest in politics. The first group was composed of 14 participants who were interested in politics ( 7 female and 7 male; 3 in the age range of 20-29, 5 in 30-39, 1 in 40-49, 4 in 50-59, and 1 over 60). The second group was composed of 15 participants who were not interested in politics ( 8 female and 7 male; 3 in the age range of 20-29, 6 in 30-39, 1 in $40-49,4$ in 5059, 1 in 60+). Participants were shown a 2-minute fragment of the 2015 UK General Election ITV Leaders' Debate (aired on 2 April 2015). They were introduced to each of the three visualisation tools in Figures 2 to 4 and given between 5 and 7 minutes to use them to explore the same 2-minute debate fragment. Immediately after using each tool, they completed the UEQ.

\subsection{Results}

We present the results of the User Experience Questionnaire using Schrepp et al.'s [40] responses analysis suite. The suite calculates the mean scores between -3 (horribly bad) and +3 (extremely good) for the 26 evaluation items, for the six scales and for three pragmatic and hedonic quality aspects described above. Following the authors' guidelines, it is worth noting that in real applications people avoid extreme answers, so mean results above +2 or below -2 are extremely unlikely, and a mean of +1.5 should be interpreted as very good evaluation. The UEQ results are followed by the results from the question to track the effects of using each tool, also for politically interested and uninterested users separately.

Figures 5 and 6 summarise the User Experience Questionnaire results for the Arguments Tree visualisation tool, respectively, for politically interested and uninterested users. The mean values for each of the items in the UEQ are on the table at the top-left of the figures. Green arrows indicate positive evaluations, yellow arrows are neutral evaluations, and red arrows are negative evaluations.

With users interested in politics, the tool scored positively for all items, with 8 of the 26 scoring above the 0.8 threshold: understandable, easy to learn, good, practical, organised, attractive, friendly and innovative. When aggregated in the six categories, the scores are still positive but all of them fall in the neutral zone. The highest is Novelty and the lowest Dependability. This is consistent with the scores in the Pragmatic and Hedonic qualities: a slightly lower score in Pragmatic quality suggests participants liked and enjoyed using the tool but are less certain about its practicality.

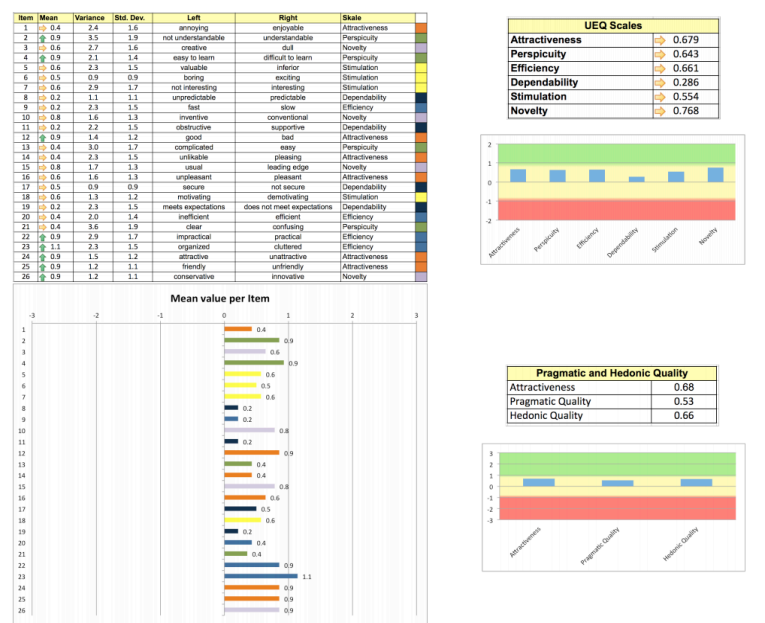

Figure 5. User Experience Questionnaire results for the Arguments Tree visualisation tool (politically interested users).

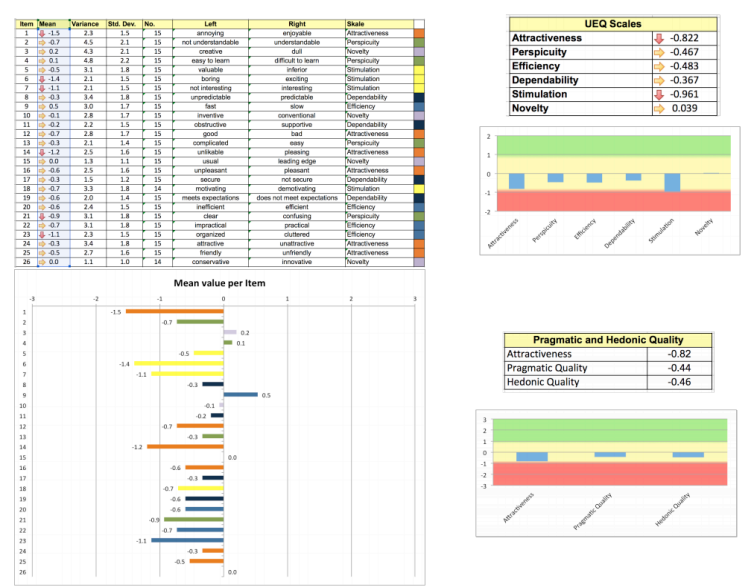

Figure 6. User Experience Questionnaire results for the Arguments Tree visualisation tool (politically uninterested users).

The landscape is remarkably different with users not interested in politics. All but 3 of the items scored negative or zero, with 6 of them below the -0.8 threshold: annoying, boring, not interesting, unlikable, confusing and cluttered. These translate into negative scores for five of the six categories, 
except for Novelty that made it slightly above zero. Two of the categories, Attractiveness and Stimulation, scored below the -0.8 threshold, meaning they received negative evaluations. Consequently, the tool scored negatively in Attractiveness and neutral (but also negative) in Pragmatic and Hedonistic quality.

Results of the sensemaking effect questionnaire for the Argument Tree visualisation tool, respectively, for politically interested and uninterested users are consistent with the UEQ figures. Users interested in politics responded more positively to the tool while those not interested strongly disagreed, disagreed or didn't know whether the tool had a positive impact in their experience of the debate.

For instance in the group of people interested in politics $50 \%$ thought that the tool helped them to reflect in a deeper way, against $20 \%$ in the group of people not interested in politics. It is worth noting that across both groups $38-40 \%$ of users either agreed or strongly agreed that the tool provided them with unexpected insights on the political debate. In the same way, though, 38-40\% across both groups found that using the tool interfered with their viewing experience. This may suggest that intrusiveness and novelty of insights are two characteristics of the tool that are independent from users' political interest.

We carried out the same analyses for the Performance Analysis and Reflections Radar with similar results. We do not report on this in detail here for reasons of space, but the data and results are available at http://edv-project.net/ueq-results/.

\section{Discussion}

A plethora of information streams are increasingly available to the audience of televised political debates. These are both produced and accessible from a variety of ubiquitous devices and are used to explore and participate in televised media events. The lack of organisation and structure between the many information streams and a televised event can make the viewing experience confusing and overwhelming, which is detrimental to citizens' adoption of such enhancements, often increasing disengagement with political processes and reducing the quality of democratic participation.

The results above show rather clearly that tools that couple information streams with political events are quite unlikely to appeal to those who are not interested in politics. The consistent, remarkable difference in assessment of the three visualisations we tested points in this direction. The results from participants interested in politics were consistently more positive for the three tools, although the majority were within the neutral zone (yellow in Figures 5 and 6). The Arguments Tree visualisation in particular scored positively across all items, scales and qualities. The Speaker Performances Panel scored fully within the neutral evaluation zone, with slightly negative results for Attractiveness and Perspicuity, and a more positive result for Novelty. The Audience Reflections Radar scored quite positively in Novelty, but almost equally negatively in Perspicuity, meaning that participants found it innovative and creative but hard to learn and understand.

These results indicate that although users saw the potential of the tools to inform them in new ways, they were not entirely at ease with the experience they were offered. With this in mind, we decided to redesign the visualisations in a more intuitive, hierarchical structure, introducing informational elements more gently (much in the same way as in the Arguments Tree). Also - and crucially - we decided to present Democratic Replay via a set of questions that citizens might have in connection with election debates, which can be answered by these tools. This will make users aware of what the tool can do for them by the time they arrive at a visualisation. Also, interactive elements will be introduced by means of hover-over tips, with suitable legends throughout.

\section{Conclusions and Future Work}

In this paper we presented Democratic Replay: an interactive video replay platform in which information channels can be stored and visualised time-linked with the video of a televised election debate. Democratic Replay enables a consistent, structured and customisable enhanced viewing experience, and builds a persistent resource that preserves the synchronisation between the televised event and the many additional information channels. We have motivated the need of such platform in response of existing research gaps in the fields of television and the internet, political communication, and hypermedia. Moreover, we have identified the main challenges that the platform aims to address and described the platform's design, its interactive analytics visualisations, and the architecture leading to the front end.

In the longer run, further efforts include the addition of extra analytics and visualisations channels (e.g. topical analysis, integration with Twitter streams and Twitter sentiment analysis, etc.; see Figure 1) and functionalities to make hypervideo and visualisations publicly available as reusable open 
data. Also, we will explore the possibility of making the contents in Democratic Replay available as soon as possible after the live event takes place. For the analyses and visualisations described in this paper, this involves live mapping of arguments, rapid analysis and annotation of the speakers' performances, and automatic analysis and visualisation of audience feedback.

Overall our work confirms previous research $[6,12,14]$ and suggests that second screen interactive experiences, despite their novelty and attractiveness, still distract the audience on the content of the replay. So this remains a key future challenge to be addressed by second screen user experience designers. At the same time the evaluation showed that interactive visualisations could offer a positive user experience to the users that already have an interest in politics, while they can be off-putting and negatively perceived by people that have no interest in politics. This is a key finding, which suggests that second screen experiences for political communication need to be tailored and customised to the user's interest in politics, especially if they are meant to be used as instruments to stimulate citizen engagement in political media events.

\section{Acknowledgements}

We would like to thank our colleagues in the Election Debate Visualisation project, Prof Stephen Coleman, Prof Simon Buckingham Shum, Dr Giles Moss, and Dr Paul Wilson for constructive feedback and discussions that greatly contributed to this work. This research was funded by the UK Engineering and Physical Sciences Research Council (EPSRC) under grant EP/L003112/1, and supported in part by the Volkswagen Foundation (VolkswagenStiftung) under grant 92182.

\section{References}

[1] Stephen Coleman and Jay G. Blumler. Leaders in the Living Room: the Prime Ministerial debates of 2010: evidence, evaluation and some recommendations. Reuters Institute for the Study of Journalism, University of Oxford, 2011.

[2] Jay G. Blumler and Stephen Coleman. Voters' responses to the Prime Minister debates: A rock of (future?) ages, pp. 35-54. Leaders in the Living Room: the Prime Ministerial debates of 2010: evidence, evaluation and some recommendations, 2010.

[3] Nic Newman. \#UKelection2010, Mainstream Media and the Role of the Internet: how social and digital media affected the business of politics and journalism. University of Oxford, Reuters Institute for the Study of Journalism, 2010

[4] Nick Anstead and Ben O'Loughlin. The Emerging Viewertariat and BBC Question Time: Television Debate and Real-Time Commenting Online. The Int. Journal of Press/Politics, 2011.

[5] Mitchell S. McKinney, J. Houston, B. and Hawthorne, J. Social Watching a 2012 Republican Presidential Primary Debate. American Behavioral Scientist, 58(4):556-573, 2014.

[6] Evelien D'heer and Cédric Courtois. The changing dynamics of television consumption in the multimedia living room. Convergence: The International Journal of Research into New Media Technologies, pages 1-16, 2014.

[7] European Telecommunications Standards Institute. Hybrid Broadcast Broadband TV 2.0 - Technical Specification, February 2015.

[8] Toni Bibiloni, Miquel Mascaro, Pere Palmer, and Antoni Oliver. A second-screen meets hypervideo, delivering content through HbbTV. In Proceedings of the ACM International Conference on Interactive Experiences for TV and Online Video, pages 131-136. ACM, 2015.

[9] Pablo Cesar and David Geerts. Social interaction design for online video and television. 2015.

[10] Dan Olsen, Benjamin Sellers, and Trent Boulter. Enhancing interactive television news. In Proceedings of the ACM International Conference on Interactive Experience of Television and Online Video (TVX2014), pages 11-18. ACM, 2014.

[11] Lyndon Nixon, Vasileios Mezaris, and Jan Thomsen. Seamlessly interlinking TV and web content to enable linked television. In ACM Int. Conf. on Interactive Experiences for Television and Online Video (TVX 2014), Adjunct Proceedings, Newcastle Upon Tyne, UK, 2014.

[12] David Geerts, Rinze Leenheer, and Dirk De Grooff. In Front of And Behind The Second Screen: Viewer and Producer Perspectives on a Companion App. In Proceedings of the ACM International Conference on Interactive Experience of Television and Online Video (TVX2014), 2014.

[13] Anna De Liddo, Brian Plüss, and Paul Wilson. 2017. A Novel Method to Gauge Audience Engagement with Televised Election Debates through Instant, Nuanced Feedback Elicitation. In Proceedings of C\&T '17, Troyes, France, June 26-30, 2017.

[14] Michael E Holmes, Sheree Josephson, and Ryan E Carney. Visual attention to television programs with a second-screen application. In Proceedings of the Symposium on Eye Tracking Research and Applications, pages 397-400. ACM, 2012. 
[15] Stephen Coleman. Debate on Television The Spectacle of Deliberation. Television \& New Media, 14(1):20-30, 2013.

[16] Douglas M McLeod and Elizabeth M Perse. Direct and indirect effects of socioeconomic status on public affairs knowledge. Journalism \& Mass Communication Quarterly, 71(2):433-442, 1994.

[17] Hai Tran. Does exposure to online media matter? The knowledge gap and the mediating role of news use. International Journal of Communication, 7:22, 2013.

[18] Mitchell S McKinney, Leslie A Rill, and Esther Thorson. Civic engagement through presidential debates young citizens' political attitudes in the 2012 election. American Behavioral Scientist, 58(6):755-775, 2014.

[19] Stephen Coleman. New mediation and direct representation: reconceptualizing representation in the digital age. New Media \& Society, 7(2):177-198, 2005.

[20] Steven Barnett. New Media, Old Problems New Technology and the Political Process. European Journal of Communication, 12(2):193-218, 1997.

[21] Stephen Coleman. Can the new media invigorate democracy? The Political Quarterly, 70(1):16-22, 1999.

[22] Matthew Hale, Juliet Musso, and Christopher Weare. Developing digital democracy: evidence from Californian municipal web pages. Digital democracy: Discourse and decision making in the information age, pages 96-115, 1999.

[23] Rostiashvili, K. Information Society and Digital Democracy-Theoretical Discourse. Journal in Humanities, 1(1):11-15, 2012.

[24] Samra Mujacic, Matjaz Debevc, Primoz Kosec, Marcus Bloice, and Andreas Holzinger. Modeling, design, development and evaluation of a hypervideo presentation for digital systems teaching and learning. Multimedia Tools and Applications, 58(2):435-452, 2012.

[25] Jakob Nielsen. Multimedia and hypertext: The Internet and beyond. Morgan Kaufmann, 1995.

[26] Nitin Sawhney, David Balcom, and Ian Smith. HyperCafe: narrative and aesthetic properties of hypervideo. In Proceedings of the 7th ACM conference on Hypertext, pages 1-10. ACM, 1996.

[27] Anna Weston. The Evolution of Hypervideo. Technical Report, University of Southampton, January 2013.

[28] Olivier Aubert and Yannick Prié. Advene: an opensource framework for integrating and visualising audiovisual metadata. In Proceedings of the 15th
International Conference on Multimedia, pages 1005-1008. ACM, 2007.

[29] Aubert, O. and Prié, Y. Advene: active reading through hypervideo. In Proceedings of the sixteenth ACM conference on Hypertext and hypermedia, pages 235-244. ACM, 2005.

[30] Albert Selvin, Simon Buckingham Shum, Maarten Sierhuis, Jeff Conklin, Beatrix Zimmerman, Charles Palus, Wilfred Drath, David Horth, John Domingue, Enrico Motta, and Gangminn Li. Compendium: Making meetings into knowledge events. In Knowledge Technologies, Austin, Texas, 2001.

[31] Helen Bailey, Michelle Bachler, Simon Buckingham Shum, Anja Le Blanc, Sita Popat, Andrew Rowley, and Martin Turner. Dancing on the Grid: using e-Science tools to extend choreographic research. Philosophical Transactions of the Royal Society A: Mathematical, Physical and Engineering Sciences, 367(1898):2793-2806, 2009.

[32] Moss, G. and Coleman, S. Rethinking Election Debates: What Citizens Are Entitled to Expect. Int. Journal of Press/Politics, 21 (1):3-24, 2016.

[33] Simon Buckingham Shum. The roots of computer supported argument visualization. In Visualizing Argumentation, pages 3-24. Springer, 2003.

[34] Werner Kunz and Horst WJ Rittel. Issues as elements of information systems, volume 131. Institute of Urban and Regional Development, University of California Berkeley, California, 1970.

[35] E Jeffrey Conklin and Jeffrey Conklin. Dialogue mapping: Building shared understanding of wicked problems, volume 668. Wiley Chichester, 2006.

[36] Alexandra Okada, Simon Buckingham Shum, and Tony Sherborne. Knowledge Cartography: software tools and mapping techniques. Springer, 2014.

[37] Kimberly A Neuendorf. The content analysis guidebook. Sage publications, 2016.

[38] Klaus Krippendorff. Content analysis: An introduction to its methodology. Sage, 2004.

[39] Bettina Laugwitz, Theo Held, and Martin Schrepp. Construction and evaluation of a user experience questionnaire. In Symposium of the Austrian HCI and Usability Engineering Group, pages 63-76. Springer, 2008.

[40] Martin Schrepp, Andreas Hinderks, and Jörg Thomaschewski. Applying the user experience questionnaire (UEQ) in different evaluation scenarios. In International Conference of Design, User Experience, and Usability, pages 383-392. Springer, 2014. 